Daniel Arruda Nascimento

\title{
Ipseidade e alteridade em Heidegger e Kierkegaard
}

Dissertação de Mestrado

Dissertação apresentada como requisito parcial para obtenção do título de Mestre pelo Programa de PósGraduação em Filosofia da PUC-Rio.

Orientador: Paulo César Duque Estrada

Rio de Janeiro

Fevereiro de 2007 
Daniel Arruda Nascimento

\section{Ipseidade e alteridade em Heidegger e Kierkegaard}

Dissertação apresentada como requisito parcial para obtenção do título de Mestre pelo Programa de PósGraduação em Filosofia da PUC-Rio. Aprovada pela Comissão Examinadora abaixo assinada.

Paulo César Duque Estrada

Orientador

Departamento de Filosofia - PUC-Rio

Eduardo Jardim de Moraes Departamento de Filosofia - PUC-Rio

Ricardo Quadros Gouvêa Universidade Federal de Juiz de Fora

Paulo Fernando Carneiro de Andrade Coordenador Setorial do Centro de Teologia e Ciências Humanas - PUC-Rio 
Todos os direitos reservados. É proibida a reprodução total ou parcial do trabalho sem autorização da universidade, do autor e do orientador.

\section{Daniel Arruda Nascimento}

Bacharel pela Faculdade de Direito da Universidade Federal Fluminense.

Ficha Catalográfica

Nascimento, Daniel Arruda

Ipseidade e alteridade em Heidegger e Kierkegaard / Daniel Arruda Nascimento; orientador: Paulo César Duque Estrada. Rio de Janeiro: PUC, Departamento de Filosofia, 2007.

$107 \mathrm{f} . ; 30 \mathrm{~cm}$.

Dissertação (mestrado) - Pontifícia Universidade Católica do Rio de Janeiro, Departamento de Filosofia.

Inclui referências bibliográficas.

1. Filosofia - Teses. 2. Ética e filosofia política. 3. Fenomenologia. 4. Existência. 5. Ipseidade. 6. Alteridade. I. Duque Estrada, P. C. (Paulo César). II. Pontifícia Universidade Católica do Rio de Janeiro. Departamento de Filosofia. III. Título.

CDD: 100 


\section{Agradecimentos}

Ao meu orientador Paulo César, aos professores Eduardo, Ricardo e Edgar, às secretárias Edna e

Diná. Aos amigos da SOBRESKI - Sociedade Brasileira de Estudos de Kierkegaard, especialmente aos professores Álvaro e Jorge. Aos meus pais, Graça e Paulo, à minha irmã Thais. Aos amigos Fábio e Rafael. À CAPES - Coordenação de Aperfeiçoamento de Pessoal de Nível Superior. 


\section{Resumo}

Nascimento, Daniel Arruda; Duque Estrada, Paulo César. Ipseidade e alteridade em Heidegger e Kierkegaard. Rio de Janeiro, 2007. 107 p. Dissertação de Mestrado - Departamento de Filosofia, Pontifícia Universidade Católica do Rio de Janeiro.

Tem a presente pesquisa o escopo de examinar as relações entre ipseidade e alteridade, tendo como ponto de partida o terreno em que Martin Heidegger e Søren Kierkegaard desenvolvem seus pensamentos. O que se pretende ao longo da dissertação é discutir a possibilidade de acesso à ipseidade a partir de uma noção de existência que compreenda a tensão que descola ipseidade e existência. Tomando como referência a análise que deita suas raízes sobre uma leitura fenomenológica da existência e percorre diferentes traços da constituição ontológica do ente que existe, procuro demonstrar, com escólio nas concepções filosóficas de Heidegger e Kierkegaard, que o acesso à ipseidade se dá na relação de alteridade.

\section{Palavras-chave}

Ética e filosofia política. Existência; ipseidade; alteridade. 


\section{Abstract}

Nascimento, Daniel Arruda; Duque Estrada, Paulo César. Ipseity and alterity in Heidegger and Kierkegaard. Rio de Janeiro, 2007. 107 p. Dissertação de Mestrado - Departamento de Filosofia, Pontifícia Universidade Católica do Rio de Janeiro.

The objective in the present dissertation is to examine the relation between ipseity and alterity, having Martin Heidegger's and Søren Kierkegaard's philosophys as a starting point. It intends to discuss on this paper the possibility of finding access to ipseity taking as reference a certain notion of existence which comprehends the tension that sets ipseity apart from existence. In this way the research brings us to the following conclusion: the access to ipseity comes from the relation to alterity.

\section{Key-words}

Ethics and political philosophy. Existence; ipseity; alterity. 


\section{Índice}

$\begin{array}{ll}\text { Intróito } & 09\end{array}$

$\begin{array}{ll}\text { Capítulo I } & 14\end{array}$

$\begin{array}{ll}\text { 1. Ipseidade fugidia } & 14\end{array}$

2. O fenômeno da multidão 20

3. Angústia 27

Capítulo II $\quad 32$

1. O fenômeno da produtividade técnico-científica e o apelo do ser 32

2. O pensamento da morte 41

3. Discurso 47

4. Silêncio 53

$\begin{array}{ll}\text { 5. Desespero } & 60\end{array}$

Capítulo III $\quad 66$

1. Alteridade 66

2. Diferença

3. Infinito 78

4. Coexistência $\quad 83$

$\begin{array}{ll}\text { Considerações finais } & 96\end{array}$

$\begin{array}{ll}\text { Referências bibliográficas } & 100\end{array}$

$\begin{array}{ll}\text { Fontes primárias } & 100\end{array}$

$\begin{array}{ll}\text { Fontes secundárias } & 102\end{array}$

$\begin{array}{ll}\text { Bibliografia complementar } & 104\end{array}$ 
Mais que as ondas do largo oceano

e que as nuvens nos altos ventos,

corre a multidão.

Mais que o fogo em floresta seca,

luminosos, flutuantes, desfrisados vestidos

resvalam sucessivos,

entre as pregas, os laços, as pontas soltas

dos emaranhados turbantes.

Aonde vão esses passos pressurosos, Bhai?

A que encontro? a que chamado?

em que lugar? por que motivo?

Bhai, nós, que parecemos parados,

por acaso estaremos também,

sem o sentirmos,

correndo, correndo assim, Bhai, para tão longe,

sem querermos, sem sabermos para onde,

como água, nuvem, fogo?

Bhai, quem nos espera, quem nos receberá,

quem tem pena de nós,

cegos, absurdos, erráticos,

a desabarmos pelas muralhas do tempo?

Cecília Meireles

Multidão in Poemas escritos na Índia in Doze noturnos da Holanda e outros poemas, p. 38. 